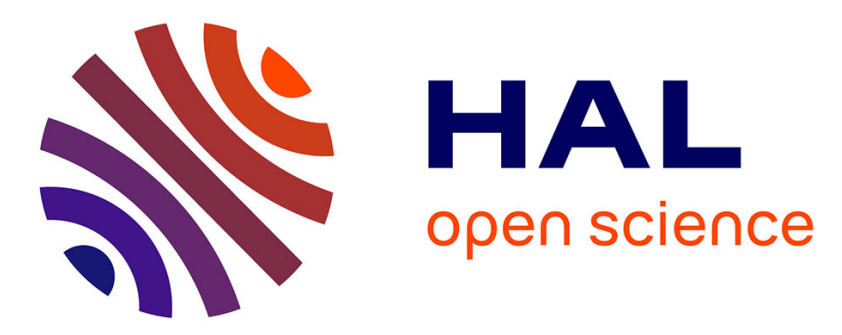

\title{
Numerical simulation of conduction and low-frequency noise in polysilicon thin film transistors
}

Abdelmalek Boukhenoufa, Christophe Cordier, Laurent Pichon, Bogdan Cretu

\section{To cite this version:}

Abdelmalek Boukhenoufa, Christophe Cordier, Laurent Pichon, Bogdan Cretu. Numerical simulation of conduction and low-frequency noise in polysilicon thin film transistors. Thin Solid Films, 2007, 515, pp.7556. 10.1016/j.tsf.2006.11.162 . hal-00171471

\section{HAL Id: hal-00171471 \\ https://hal.science/hal-00171471}

Submitted on 12 Sep 2007

HAL is a multi-disciplinary open access archive for the deposit and dissemination of scientific research documents, whether they are published or not. The documents may come from teaching and research institutions in France or abroad, or from public or private research centers.
L'archive ouverte pluridisciplinaire HAL, est destinée au dépôt et à la diffusion de documents scientifiques de niveau recherche, publiés ou non, émanant des établissements d'enseignement et de recherche français ou étrangers, des laboratoires publics ou privés. 


\title{
NUMERICAL SIMULATIONS OF CONDUCTION AND LOW-FREQUENCY NOISE IN POLYSILICON THIN FILM TRANSISTORS
}

\author{
A. Boukhenoufa, C. Cordier, L. Pichon ${ }^{*}$, B. Cretu \\ Groupe de Recherches en Informatique, Image, Automatique et Instrumentation de Caen \\ (GREYC), CNRS UMR 6072, ENSICAEN-Université de Caen, 6 bd du Maréchal Juin, 14050 \\ Caen Cedex 5, France. \\ *Groupe Microélectronique, IETR, UMR CNRS 6164, campus de beaulieu, 35042 Rennes cedex, \\ France
}

\begin{abstract}
Numerical simulations of static conduction and low-frequency noise are carried out in $\mathrm{N}$-channel polysilicon thin film transistors. The Meyer-Neldel effect associated with the drain current is related to trapping/detrapping processes of carriers from dangling bonds located at the interface. Lowfrequency noise is simulated by generation-recombination processes. The sources responsible of noise in the thin film transistors are mainly located close to the interface. The microscopic parameter deduced from numerical simulation is lower than the macroscopic one deduced from noise measurements. The ratio of these two parameters is considered as a factor of merit to qualify thin film transistor technology.
\end{abstract}

\section{Introduction}

Polysilicon thin-film transistors (TFTs) are key elements for large area electronics because of their high potential usefulness in driving circuits and in addressing pixels. Some improvements remain because electrical properties are strongly affected by defects in polysilicon. A well understood of transport characteristic in TFTs is necessary to improve device modelling and TFT technologies. In this paper we study, the impact of the defects, in terms of nature (strained or dangling bonds) and spatial localization within the active layer, on the electrical behaviour of TFTs biased from weak to strong inversion, and operating in the linear mode. 


\section{Simulated devices}

The simulated device cross section of the TFTs is shown in the insert of the figure 1 . The doped and undoped polycrystalline regions are $150 \mathrm{~nm}$ thick. The oxide thickness $\mathrm{t}_{\mathrm{ox}}$ is $60 \mathrm{~nm}$, the length and width of the channel are $20 \mu \mathrm{m}$ and $50 \mu \mathrm{m}$ respectively. The polycrystalline silicon in the channel is described by equally spaced grain boundaries (GBs) perpendicular to the direction of carrier propagation from drain to source. The grain boundary is depicted as thin amorphous silicon with a width of $2 \mathrm{~nm}$. The grain size is $300 \mathrm{~nm}$. Geometrical dimensions of each part of the structure correspond to those of processed TFTs (see ref [1]).

\section{Physical models for simulations}

Simulations of carrier transport, distribution of traps, and low-frequency noise were made by using the DESSIS-ISE multi-dimensional simulator of ISE-TCAD software [2].

\section{A- Carrier transport}

In simulations we used a Drift-Diffusion (DD) model. The governing equations for charge transport are the Poisson equation and the carrier continuity equations.

\section{B- Trap state distributions}

Band tail state distributions associated with strained bond-type defects are described by:

$N_{s b}(E)=N_{\text {max }}^{a} \exp \left\{-\left|\left(E_{c}-E\right) / E_{s a}\right|\right\}+N_{\text {max }}^{d} \exp \left\{-\left|\left(E-E_{v}\right) / E_{s d}\right|\right\}$

and trap state distributions associated with dangling bonds are given by:

$\mathrm{N}_{d b}=N_{d b}^{a} \exp \left\{-\left(E_{D}-E\right)^{2} / 2 \sigma_{d b}^{2}\right\}+N_{d b}^{d} \exp \left\{-\left(E-E_{D}\right)^{2} / 2 \sigma_{d b}^{2}\right\}$

Indexes a and $\mathrm{d}$ refer respectively to the acceptor-like and the donor-like states. $\mathrm{N}_{\max }^{\mathrm{a}, \mathrm{d}}$ and $\mathrm{E}_{\mathrm{sa}, \mathrm{d}}$ are the characteristic parameters of the band tail states distribution. $\mathrm{N}_{\mathrm{db}}^{\mathrm{a}, \mathrm{d}}$ stands for the 
maximum density of deep trap states at the energy bandgap level $E_{D}$ and $\sigma_{d b}$ is the characteristic energy.

\section{C- Low frequency noise}

The noise simulation in ISE-TCAD simulator is based on the impedance field method (IFM) of Shockley. A numerically efficient Green function approach to the Langevin equation-based simulation of the IFM is the basis for the implementation in ISE simulator. The complex Green functions $\mathrm{G}$ describe the propagation of perturbations inside the device to the contacts. The noise voltage spectral density was calculated from integration over all noise sources:

$$
S(\omega, r)=\sum_{\alpha=n, p} \int_{\Omega} G_{\alpha} K_{\alpha, \alpha}^{G R} G_{\alpha}^{*} d r+\sum_{\alpha=n, p} \int_{\Omega} G_{\alpha} K_{\alpha, \alpha}^{f G R} G_{\alpha}^{*} d r
$$

where $\mathrm{K}^{\mathrm{GR}}, \mathrm{K}^{\mathrm{fGR}}$ and $\Omega$ represent respectively, the Generation-Recombination (GR) and the flicker GR local noise sources and the device volume. The GR noise source model is expressed as a tensor:

$$
K_{n, n}^{G R}=\frac{J_{n} \otimes J_{n}}{n} \frac{4 \alpha_{g r} \tau_{g r}}{1+\omega^{2} \tau_{g r}^{2}}
$$

$\mathrm{J}_{\mathrm{n}}$ is the local current density, $\mathrm{n}$ the local carrier density, $\tau_{\mathrm{gr}}$ the equivalent GR lifetime, $\alpha_{\mathrm{gr}}$ a constant which represents the quasi Poissonian character of the carrier number $(\mathrm{N})$ fluctuations ( $\operatorname{var} \Delta N=\alpha_{g r} \Delta N$ ), and $\omega$ the angular frequency. The $1 / \mathrm{f}$ noise source is represented as the sum of GR noises produced by sub bands of impurities or defects, with a continuous distribution of relaxation times between $\tau_{1}$ and $\tau_{2}: g(\tau)=\left(\ln \left(\tau_{2} / \tau_{1}\right) \tau\right)^{-1}$. The flicker GR local noise source is given by a tensor:

$$
K_{n, n}^{f G R}=\frac{J_{n} \otimes J_{n}}{n} \frac{2 \alpha_{H}}{\pi f \log \left(\frac{\tau_{2}}{\tau_{1}}\right)}\left[\arctan \left(\omega \tau_{2}\right)-\arctan \left(\omega \tau_{1}\right)\right]
$$

$\alpha_{\mathrm{H}}$ is the microscopic Hooge noise parameter associated with the local source of noise. 


\section{Results and discussion}

\subsection{Electrical conduction}

Simulated transfer characteristics were fitted with experimental data issued from Si-poly TFTs (see figure 1) considering strained bonds at the interface with defect distribution parameters given as reference values: $\mathrm{N}_{\text {max }}^{\mathrm{a}}=2.2 \times 10^{14} \mathrm{~cm}^{-2} \mathrm{eV}^{-1}, \mathrm{E}_{\mathrm{sa}}=0.085 \mathrm{eV}, \mathrm{N}_{\max }^{\mathrm{d}}=5 \times 10^{17} \mathrm{~cm}^{-2} \mathrm{eV}^{-1}$. Moreover, the experimental drain current follows the Meyer-Neldel (MN) rule $[3,4]$ :

$$
\left\{\begin{array}{l}
I_{D}=\beta\left(V_{G S}-V_{O}\right) \exp \left(-\frac{E_{A}}{k T}\right) \\
\beta=\beta_{O}\left(V_{D S}\right) \exp \left(\frac{E_{A}}{E_{M N}}\right)
\end{array}\right.
$$

with $\mathrm{E}_{\mathrm{A}}$ the activation energy decreasing with the gate voltage, $\mathrm{E}_{\mathrm{MN}}$ the $\mathrm{MN}$ characteristic energy, and $\beta_{0}\left(\mathrm{~V}_{\mathrm{DS}}\right)$ the transconductance. $\mathrm{MN}$ effect is related to multiple-trapping transport [5], and $\mathrm{E}_{\mathrm{MN}}(\approx 0.045 \mathrm{eV})$ is related to process fabrication parameters [6]. The analysis of the $\mathrm{MN}$ effect on the drain current is associated with the study of the $\mathrm{E}_{\mathrm{A}} / \mathrm{E}_{\mathrm{MN}}$ ratio with trap state distribution parameters. Subsequently we analyze the MN effect by numerical simulation and results are presented at $\mathrm{V}_{\mathrm{GS}}=1 \mathrm{~V}$.

The influence of strained bond-type defects located at the interface was first analyzed. As IDS is strongly controlled by $\mathrm{E}_{\mathrm{sa}}$ parameter whereas other parameters have a rather slight effect [6], then $\mathrm{N}_{\max }^{\mathrm{a}, \mathrm{d}}$ and $\mathrm{E}_{\mathrm{sd}}$ were fixed (reference values) and we studied the effect of $\mathrm{E}_{\mathrm{sa}}$ on $\mathrm{E}_{\mathrm{A}} / \mathrm{E}_{\mathrm{MN}}$ ratio (see figure 2 (a)). The significant increase of this ratio with $\mathrm{E}_{\mathrm{sa}}$ shows that the $\mathrm{MN}$ effect is related to strained bond-type defects located at the interface. The influence of $E_{\mathrm{sa}}$ is predominant for deep trap states in the bandgap (see insert fig. 2 (a)) and thus it is more convenient to consider dangling bonds at the interface. Then, band tails states parameters were fixed according to reference values, and we deduced the variations of $E_{A} / E_{M N}$ versus $\mathrm{N}_{\mathrm{db} 0}=\mathrm{N}_{\mathrm{db} 0}^{\mathrm{a}}=\mathrm{N}_{\mathrm{db} 0}^{\mathrm{d}}$ (figure $2(\mathrm{~b})$ ). The high rate of increase of $\mathrm{E}_{\mathrm{MN}} / \mathrm{E}_{\mathrm{A}}$ with $\mathrm{N}_{\mathrm{db} 0}$ shows the 
strong influence of transitions of carriers from deep states induced by dangling bonds located at the interface on the $\mathrm{MN}$ effect.

Next, we analyzed the influence of the traps within the grain boundaries. Band tail trap distribution parameters at the interface are fixed (reference values), and first we defined band tail traps at the grain boundaries according to typical experimental values $[3,7]$ with a symmetric distribution: $\mathrm{N}_{\operatorname{maxa}}=\mathrm{N}_{\operatorname{maxd}}=\mathrm{N}_{\max }$ and $\mathrm{E}_{\mathrm{sa}}=\mathrm{E}_{\mathrm{sd}}=\mathrm{E}_{\mathrm{s}}$. The corresponding variations of $E_{\mathrm{A}} / \mathrm{E}_{\mathrm{MN}}$ versus $E_{\mathrm{s}}$ are plotted in the figure 3 (a). No increase is observed suggesting no influence of tails states on $\mathrm{MN}$ effect. Next, band tail state distribution parameters at grain boundaries were fixed $\left(\mathrm{N}_{\max }=10^{20} \mathrm{~cm}^{-3} \mathrm{eV}^{-1} \mathrm{E}_{\mathrm{s}}=0.11 \mathrm{eV}\right)$ and we analyzed the effect of the dangling bonds. Variations of $\mathrm{E}_{\mathrm{A}} / \mathrm{E}_{\mathrm{MN}}$ versus $\mathrm{N}_{\mathrm{db} 0}$ plotted in the figure 3 (b) do not display significant increase. Thus, MN effect is not related to dangling bonds at the grain boundaries.

\section{2 Low frequency noise}

In noise simulation, we kept the distribution of tail state at the interface with reference values. The calculation of the noise spectral density requires knowledge of the local noise source K. We defined the flicker GR local noise sources $\mathrm{K}^{\mathrm{fGR}}$ within the active layer with $\alpha_{\mathrm{H}}$ assumed identical for all sources. A $1 /$ f noise spectrum is obtained in the studied frequency band $(1 \mathrm{~Hz}-$ $10^{3} \mathrm{~Hz}$ ) with the relaxation times $\tau_{1}$ and $\tau_{2}$ fixed at $10^{-7} \mathrm{~s}$ and $10^{4} \mathrm{~s}$, respectively. For spectrums which contain a Lorentzian we introduced a GR local noise source $\mathrm{K}^{\mathrm{GR}}$. A good fit of experimental with numerical noise spectra was obtained (see figure 4), and the microscopic noise parameter $\alpha_{H}$ associated with $\mathrm{K}^{\mathrm{fGR}}$ was deduced. Values of $\alpha_{\mathrm{H}}$ versus effective voltage $\left(\mathrm{V}_{\mathrm{GS}}-\mathrm{V}_{0}\right)$, with $\mathrm{V}_{0}$ the flatband voltage, are reported in figure 5 (a). Plots of macroscopic apparent noise parameter $\alpha_{\text {app }}$, deduced from measurements according to the Hooge formula $\mathrm{S}_{\mathrm{IDS}} / \mathrm{I}_{\mathrm{DS}}^{2}=\alpha_{\mathrm{app}} /(\mathrm{fN})$, is also reported. $\alpha_{\mathrm{H}}$ and $\alpha_{\text {app }}$ exhibit the same variations: it increases from weak to moderate inversion and then it decreases from moderate to strong inversion. This singular behaviour, previously reported for $\alpha_{\text {app }}$ [4], suggests that $\alpha_{H}$ and $\alpha_{\text {app }}$ are related. 
Higher values of $\alpha_{\text {app }}$ are explained by the current crowding in the device due to defects within the active layer inducing non conducting spots [8]. For homogeneous materials $\gamma=\alpha_{H} / \alpha_{a p p} \sim 1$ whereas for disordered materials $\gamma=\alpha_{H} / \alpha_{\text {app }}<<1$. For polycrystalline resistors it can be considered as a factor of quality [8]. In our case $\gamma \sim 0.17$.

We give in the figure 5 (b) the $2 \mathrm{D}$ spatial distribution in the structure of the simulated local noise voltage spectral density (LNVSD). Noise level is higher close to the interface suggesting a high contribution of the local sources of noise in this region. Although sources were defined within the active layer, but owing to the previous results and to those obtained in $\S 4.1$, we can suspect the preponderant role of dangling bonds at the interface on the $1 / \mathrm{f}$ noise level in the TFTs.

\section{Conclusions}

Numerical simulations of carrier transport in poly-Si TFT reveal that the MN effect is strongly controlled by trap state distribution rather associated with dangling bonds located at the interface. It suggests that drain current can be described by multiple trapping processes of carriers along the interface. Low frequency noise in TFTs can be simulated by GR processes of carriers, and results show that the noise level is higher close to the interface. Therefore, because of the high density of defects located in this region, 1/f noise can be explained by carrier fluctuation due to trapping/detrapping of carriers from these defects, ruling out the theory of the mobility fluctuations proposed in homogeneous sample of high crystal quality. In addition, defects in the device are responsible of overestimation of the measured 1/f noise parameter.

\section{References}

[1] J.F.Michaud, R. Rogel, T. Mohammed-Brahim, M. Sarret, O. Bonnaud, Thin Solid Films 487 (2005) 81. 
[2] DESSIS-ISE, ISE-TCAD Release 8.5, User's Manual, Zurich, 2004.

[3] C.Cordier, A.Boukhenoufa and L.Pichon, Solid State Electron, 49 (2005) 1376.

[4] A.Boukhenoufa, L.Pichon, C.Cordier, R.Carin and H.El Din Kotb, Proc. of SPIE, Vol.5470, 2004, p.546.

[5] W. B. Jackson, Phys. Rev. B, 38(5) (1988) 3595.

[6] A. Boukhenoufa, PhDThesis, Modelisation du comportement électrique dans les TFTs en silicium polycristallin : analyses experimentale et par simulation numerique de la conduction et du bruit en 1/f, University of Caen, 2005.

[7] C. A. Dimitriadis, G. Kamarinos, J. Brini, IEEE Elect. Dev. Lett., 22 (2001) 381.

[8] E. P. Vandamme, L. K. J. Vandamme, Microelectron. Reliab. , 40 (2000) 1847. 


\section{Figure captions}

Figure 1: Simulated and experimental transfer characteristics $\left(\mathrm{V}_{\mathrm{DS}}=0.3 \mathrm{~V}\right)$ versus temperature. Insert: schematic cross-section of devices for 2D simulation of TFT.

Figure 2: Variations of $\mathrm{E}_{\mathrm{A}} / \mathrm{E}_{\mathrm{MN}}$ versus trap state distribution parameters for defects located at the interface. Effect of:

(a) strained bonds (insert: corresponding interface state distributions),

(b) dangling bonds (insert: corresponding interface state distributions).

Figure 3: Variations of $\mathrm{E}_{\mathrm{A}} / \mathrm{E}_{\mathrm{MN}}$ versus grain boundary trap state distribution parameters. Effect of:

(a) strained bonds at the grain boundaries (insert: corresponding trap state distributions with $\mathrm{N}_{\text {max }}=10^{20} \mathrm{~cm}^{-2} \mathrm{eV}^{-1}, \mathrm{E}_{\mathrm{s}}=0.11 \mathrm{eV}$ ),

(b) dangling bonds at the grain boundaries (insert: corresponding trap state distributions with $\mathrm{E}_{\mathrm{D}}=0.7 \mathrm{eV}$ and $\sigma_{\mathrm{db}}=0.05 \mathrm{eV}$ ).

Figure 4: Experimental and simulated noise current spectra in TFT at different gate voltages.

Figure 5: (a) Noise parameters versus effective gate voltage, (b) two dimensional spatial distribution of local noise voltage spectral density (LNVSD) in the structure.

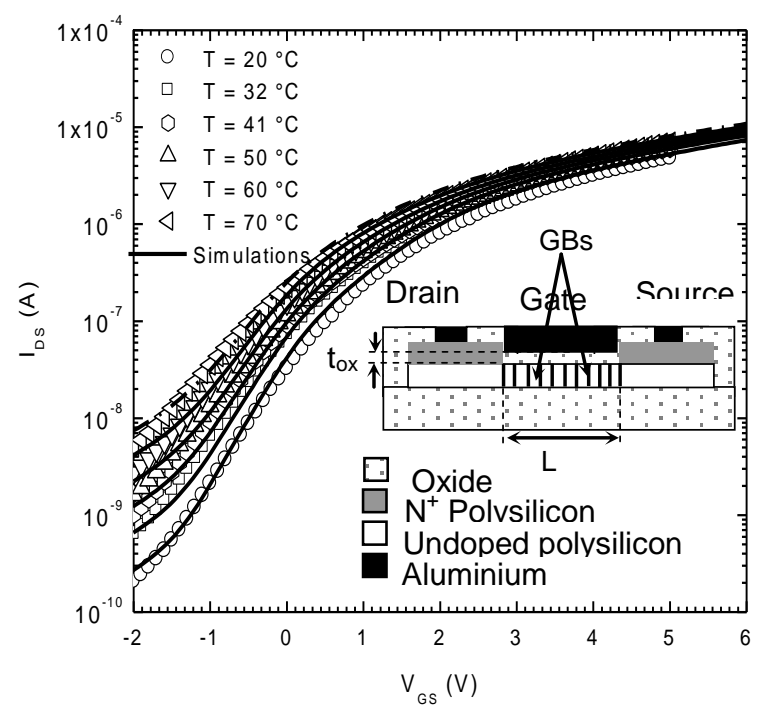

Figure 1 


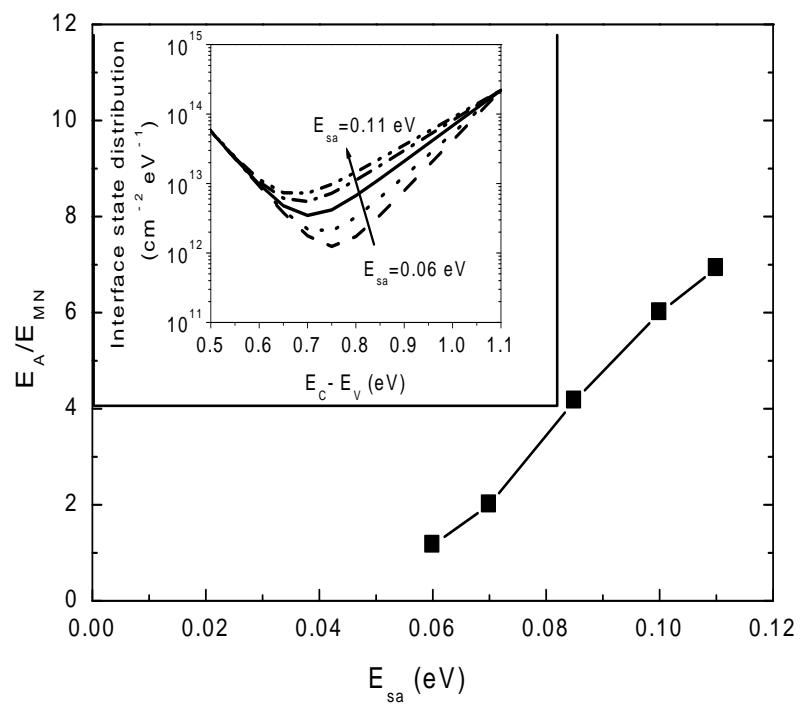

(a)

Figure 2

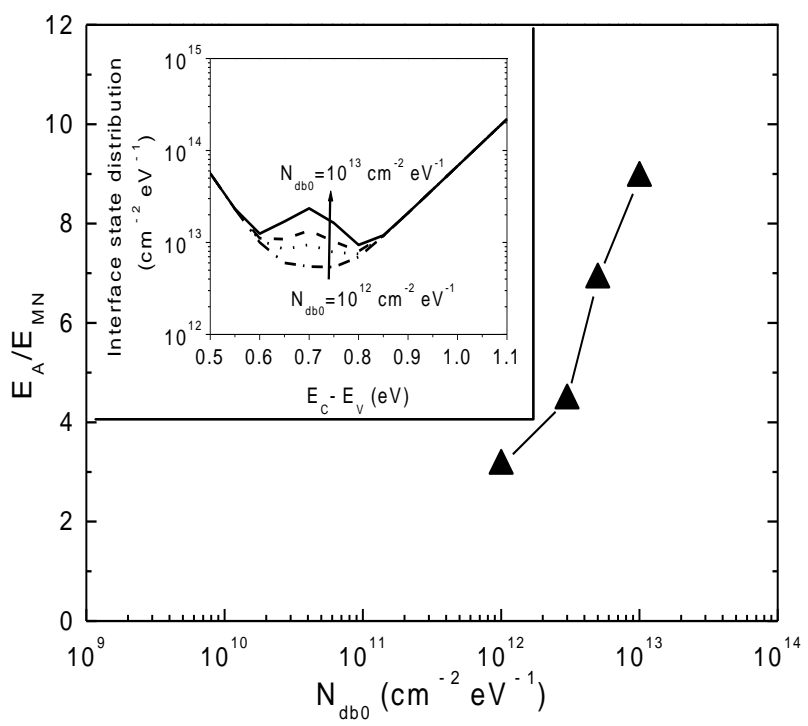

(b)

Figure 2 


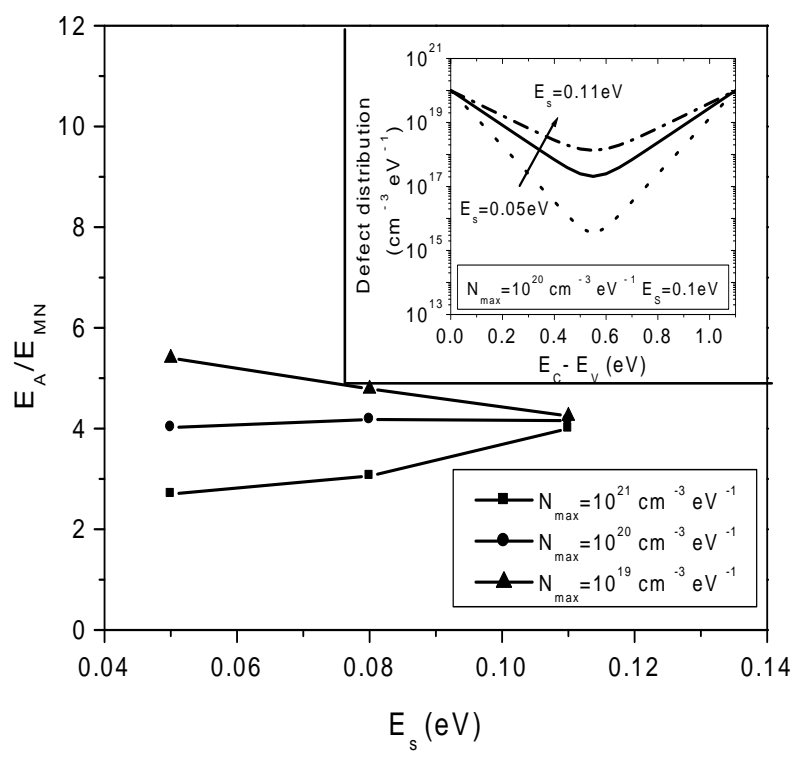

(a)

Figure 3

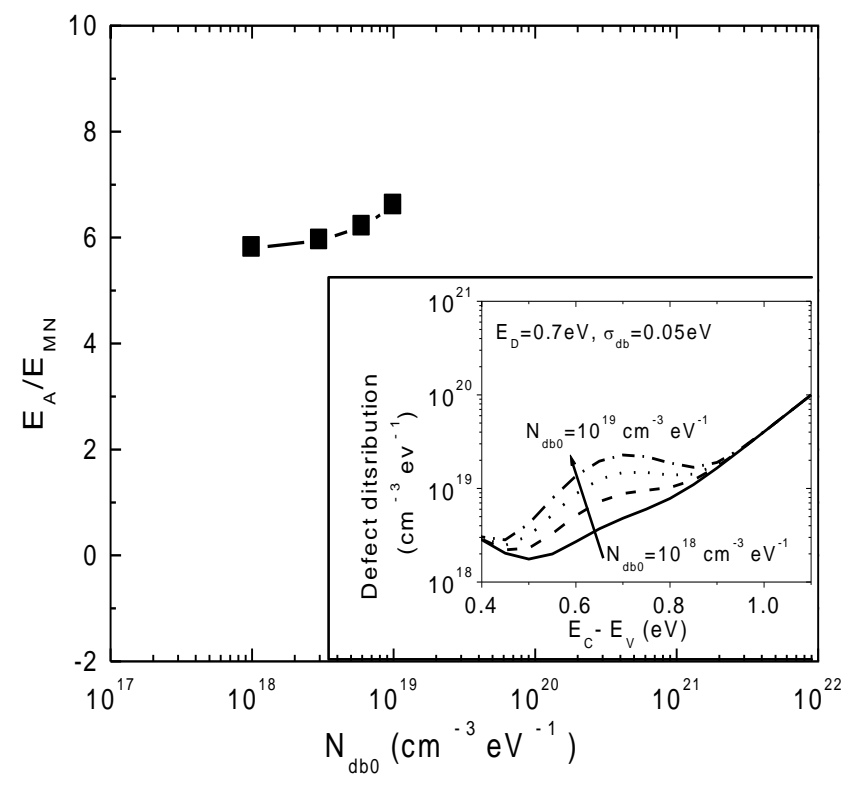

(b)

Figure 3 


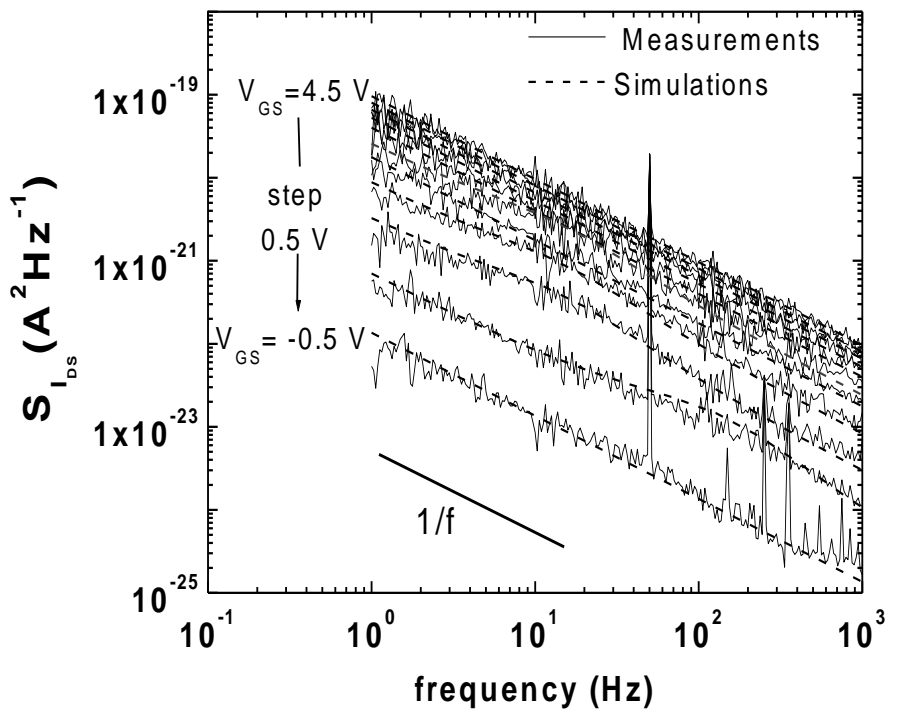

Figure 4 


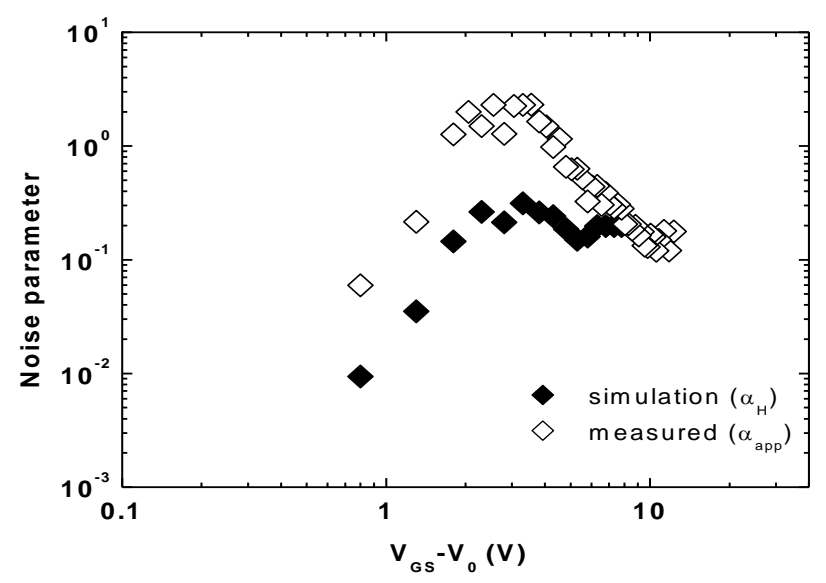

(a)

Figure 5

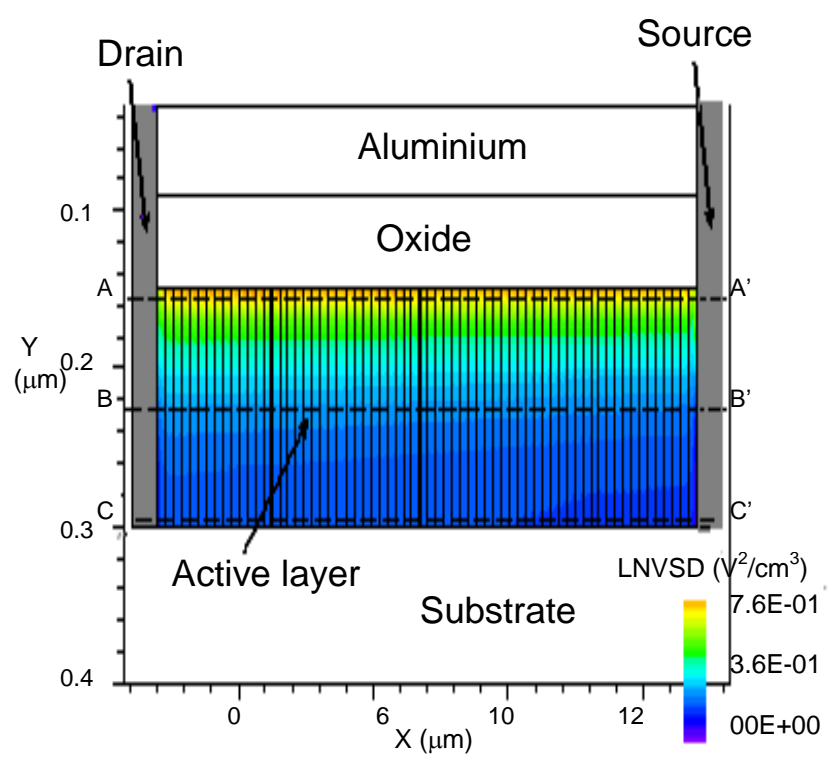

(b)

Figure 5 